\title{
Chemical conversion of paper industry effluents into carboxymethylcellulose
}

\author{
Guido Mastrantonio ${ }^{a}$, Laura Battaioto ${ }^{b}$, Carla Jones ${ }^{d}$, Marcos Coustet ${ }^{c}$, \\ Hector Chandi ${ }^{d}$, Diego K. Yamul ${ }^{b, *}$ \\ a Laboratorio de Servicios a la Industria y al Sistema Científico (LaSeISiC). Comisión de Investigaciones Científicas de \\ la Provincia de Buenos Aires (CIC-PBA) , Camino Centenario e/505 y 508 Gonnet, 1900 Buenos Aires, Argentina \\ ${ }^{\mathrm{b}}$ Centro de Investigación y Desarrollo en Criotecnología de Alimentos (CIDCA), Facultad de Ciencias Exactas, \\ Universidad Nacional de La Plata - CCT La Plata - CONICET, 47 y 116, 1900 La Plata, Argentina \\ c Instituto de Investigaciones Fisicoquímicas (INIFTA), Universidad Nacional de La Plata, Buenos Aires, Argentina \\ d Departamento de Ciencias Biológicas. Facultad de Ciencias Exactas, Universidad Nacional de La Plata, Buenos \\ Aires, Argentina
}

\begin{abstract}
A B S T R A C T
The synthesis of carboxymethylcellulose was investigated using effluents containing short cellulose fibers. Carboxymethylcellulose was synthesized according to the slurry process using different amount of sodium hydroxide and different incubation times at $30^{\circ} \mathrm{C}$ after the etherification reaction as variables. Characterization of the product was conducted by Fourier transformed infrared spectroscopy, X-ray diffraction, degree of substitution, average degree of polymerization, water imbibing capacity, color, rheological properties, apparent viscosity and trace elements content. Incubation time slightly increased the yield of the reaction and the degree of substitution during the first $12 \mathrm{~h}$. The reaction yield and degree of substitution both decreased when the initially concentration of $\mathrm{NaOH}$ was increased from $7.0 \mathrm{~g} / \mathrm{mL}$ to $10.5 \mathrm{~g} / \mathrm{mL}$. The carboxymethylcellulose obtained was darker and had lower hydration properties than commercial samples. Trace elements content suggests that the product could be only used in paint factories or building materials industries.
\end{abstract}

(๑) 2014 The Institution of Chemical Engineers. Published by Elsevier B.V. All rights reserved.

Keywords: Short cellulose fibers; Carboxymethylcellulose; Paper; Recycled sludge; Effluents; Solid Waste

\section{Introduction}

In Argentina, at least 180 million metric tons of municipal solid waste are annually generated and disposed in landfills. The opportunities for landfilling of municipal solid waste are rapidly declining with depleting available cheap land resources (Choy et al., 2004). Typically, pulp and paper derivative products constitute about $45 \%$ of the municipal waste. However, in the last decade due to environmental concerns, governmental regulations and economic considerations, there is an increased effort in the paper recycling endeavor.

In the recycled paper industry, different primary sludge grades have been defined according to the strength and length of the fibers. The paper recycling processes involve mechanical and thermal successive treatments in aqueous solution to cleave, cut and modify the original cellulose fiber. The liquid effluents generated during this process contain a significant amount of short cellulose fibers (SCF) not suitable for being incorporated into the network of recycled paper (Ochoa de Alda, 2008).

Recycled paper sludge composition is approximately $25-30 \%$ of SCF and $70-75 \%$ water. These residues are usually landfilled or incinerated after dewatering, which is costly. The conversion of waste materials into useful products would reduce the environmental impacts of paper manufacturing (Pushpamalar et al., 2006). Recommended waste water

\footnotetext{
* Corresponding author. Tel.: +54 221 4249287/4254853; fax: +54 221 4249287/4254853.

E-mail addresses: karim@biol.unlp.edu.ar, karimyamul@hotmail.com (D.K. Yamul).

Available online 8 August 2014
} 
reduction methods include the recycling of waste water with simultaneous recovery of fibers. The reuse of fibers is not always possible to be carried out in the same company where it is generated; as a consequence, a management alternative is required. The most widely researched non-conventional management alternative has been the reuse of primary sludge as feedstock in the manufacture of hardboard (Eroglu and Saatci, 1993), fiberboard (Geng et al., 2007), building materials such as cement and concrete (Naik et al., 2004), bricks (Andreola et al., 2005), and land application cover material (He et al., 2009a,b). In order to increase the options for the reuse of primary sludge new methods for recycling must be investigated.

Concerning to this point, carboxymethylcellulose (CMC) is the most widely used cellulose ether today, with applications in a large number of industries, thus, there is a high range of required qualities for this polymer. CMC was synthesized from sago waste (Pushpamalar et al., 2006), cellulosic wastes from textile and garment industries (Fakrul Alam and Mondal, 2013), water hyacinth (Barai et al., 1997) and paper sludge (He et al., 2009a,b). The slurry process (Heinze and Koschella, 2005) is used for large scale production of CMC. In this method the CMC synthesis is carried out in two steps. The first step is the basification in which cellulose is suspended in alcohol-water-sodium hydroxide system. The second step is the etherification with monochloroacetic acid. Several factors affect the carboximethylation of cellulose and the resultant properties of the CMC, such as type of solvents (Pushpamalar et al., 2006) sodium hydroxide concentration, temperature, monochloroacetic acid concentration and reaction time (Khullar et al., 2005; He et al., 2009a,b; Wang et al., 2010). At the moment no information is available about the yield of the reaction when the reaction mixture is incubated at $30^{\circ} \mathrm{C}$ after the etherification reaction at different sodium hydroxide content. Thus, the purpose of this work is to explore the effect of these variables on the yield of the reaction, degree of polymerization and degree of substitution of CMC obtained using SCF from paper recycled sludge. We also evaluated the quality of the CMC obtained by analyzing the trace element content, rheology, color and water imbibing capacity.

\section{Material and methods}

\subsection{Chemical reagents}

All chemicals used were of analytical grade. Deionized water (electrical conductivity around $0.055 \mu \mathrm{S} / \mathrm{cm}$ ) was used for atomic absorption assays. Commercial carboxymethylcellulose (Gelfix S.A, Buenos Aires, Argentina) with a degree of polymerization of 1405 and degree of substitution of 0.92 was used as reference $\left(\mathrm{CMC}_{\mathrm{R}}\right)$.

\subsection{Sampling}

The samples were obtained from a repulping plant in La Plata city (Buenos Aires, Argentina), which generates a high amount of solid by-product referred to as 'sludge effluent'. The plant has a makepaper line of tissue type with an effluent flow of $51.8 \pm 9.3 \mathrm{~m}^{3} / \mathrm{h}$. Four sampler points were selected based on their emission relevance corresponding to the cyclone, papermaker line, recuperation tank and pulp thickener effluents. The samples were collected in plastic containers $(10 \mathrm{~L})$ and stored at $4{ }^{\circ} \mathrm{C}$ until analysis.

\subsection{Sludge effluent flow measurements}

The sludge effluent flow was determined according to Bos (1989). The cellulose flow emission was estimated from the sludge effluent flow at the critical points process. The total cellulose content was determined according to the colorimetric method described by Gottipati and Mishra (2011).

\subsection{Sludge effluent analysis}

The chemical oxygen demand and sedimentable solids at 10 and 60 min were determined according to the ASTM methods (1991).

\subsection{SCF recovery}

In order to obtain the solid fraction of the crude SCF, $45 \mathrm{~mL}$ of the sludge effluent from the cyclone was decanted and centrifuged for $5 \mathrm{~min}$ at $3500 \times g$ (Rolco CM 2036, CABA, Argentina). The solid obtained was washed three times with distilled water, centrifuged, washed with methanol and dehydrated at $100^{\circ} \mathrm{C}$ to constant weight, expressed as grams per liter of effluent. It was assumed that this solid offer a good estimation of total cellulose content. The dried crude SCF has a brownish color and cotton appearance with fine in particle size.

\subsection{Carboxymethylation of crude SCF}

CMC was synthesized according to the slurry process (Heinze and Koschella, 2005) with some modifications using dry crude SCF as a raw material. Briefly, $50 \mathrm{~mL}$ of isopropanol, $2 \mathrm{~g}$ of crude dry SCF in $20 \mathrm{~mL}$ of sodium hydroxide $(7 \mathrm{~g} / 100 \mathrm{~mL}$ or $10.5 \mathrm{~g} / 100 \mathrm{~mL}$ ) were mixed in a $250 \mathrm{~mL}$ reaction vessel. After stirring 1 hour at room temperature, $10 \mathrm{~g}$ of solid monochloro acetic acid in $8 \mathrm{~mL}$ of isopropanol was slowly added and the mixtures were stirred for $3 \mathrm{~h}$ at $55^{\circ} \mathrm{C}$. The reaction mixtures were cooled down at $30^{\circ} \mathrm{C}$ and incubated up to $21 \mathrm{~h}$. After incubation or not, the reaction mixtures were centrifuged and the solid fractions were neutralized with acetic acid $(10 \mathrm{~mL} / 100 \mathrm{~mL})$. The substances obtained were dissolved in aqueous solution of potassium chloride $(1.5 \mathrm{~g} / 100 \mathrm{~mL})$, and solutions were centrifuged for elimination of insoluble impurities. Supernatants were precipitated with ethanol, washed with acetone three times and dried at $40^{\circ} \mathrm{C}$. Different samples of the reaction mixtures were assayed each $3 \mathrm{~h}$ for yield, degree of substitution and degree of polymerization. The yield (Y) was calculated according to the following equation:

$\mathrm{Y}(\%)=\left(\frac{\mathrm{mCMCt}}{\mathrm{mSCF}}\right) \times 100$

where mCMCt is the mass of CMC obtained at different times and $\mathrm{mSCF}$ is the mass of SCF used as raw material $(2 \mathrm{~g})$.

\subsection{Spectroscopic characterization}

Fourier transformed infrared spectroscopy and X-ray diffraction were carried out to verify the success of the synthesis. The measures were carried out in a Nicolet IR200 instrument (ThermoScientific, WI, USA) in the transmission mode between 500 and $4000 \mathrm{~cm}^{-1}$. The powdered dried solids were mixed with potassium bromide $(1 / 100 \mathrm{~g} / \mathrm{g})$ and grounded in an agate mortar. Twenty eight scans were collected at room temperature for each spectrum at a resolution of $4 \mathrm{~cm}^{-1}$. Deconvultion 
of the spectra was performed using the OMNIC* series software (ThermoScientific, WI, USA). X-ray diffractograms were obtained with an X'Pert PANalytical diffractometer (Almelo, The Netherlands) operating at $40 \mathrm{kV}$ and $40 \mathrm{~mA}$ with copper radiation. The samples were scanned through a $2 \theta$ (diffraction angle) range of $2-60^{\circ}$ at $0.02 \%$.

\subsection{Determination of the degree of substitution and degree of polymerization}

The degree of substitution and degree of polymerization were estimated in duplicate by spectroscopic method proposed by Pushpamalar et al. (2006) and the viscosimetric method as described by Pala et al. (2007), respectively.

\subsection{Rheological properties and determination of the apparent viscosity}

The apparent viscosities $(\eta)$ of $1.0 \mathrm{~g} / 100 \mathrm{~mL}$ aqueous solution of $\mathrm{CMC}_{\mathrm{R}}$ and the obtained $\mathrm{CMC}$ were determined at different shear rates ranging from 3.24 to $64.8 \mathrm{~s}^{-1}$ as described by Toğrul and Arslan (2003). A controlled stress Rotovisco Haake RV2 equipment (Karlsruhe, Germany) with a MK50/NV system interfaced to a computer for control and data acquisition was used. Measurements were carried out at $25 \pm 1^{\circ} \mathrm{C}$ by duplicate.

\subsection{Water imbibing capacity}

In order to evaluate the potential use of the CMC produced as a water retention agent, the water imbibing capacity was measured using a Baumann apparatus according to a method modified by Wagner et al. (1996). The method determines the spontaneous uptake of water by a sample powder at a given temperature. The water uptake of $0.0151 \mathrm{~g}$ of CMC and $0.0143 \mathrm{~g}$ of $\mathrm{CMC}_{\mathrm{R}}$ was recorded at $20^{\circ} \mathrm{C}$ until the equilibrium was reached. Practical equilibrium conditions were attained when uptake readings in the plateau zone repeated within $0.01 \mathrm{~mL}$. This criterion was used to define the water imbibing capacity, the asymptotic amount of liquid water $(\mathrm{mL})$ absorbed from the pipette per g of CMC. Determinations were carried out in duplicate.

\subsection{Color}

The color of the CMC and $\mathrm{CMC}_{\mathrm{R}}$ was measured with a Chromameter CR 300 Minolta (Osaka, Japan). Values are the average ( \pm standard deviation) of three independent replicates.

\subsection{Trace elements content}

The content of chromium ( $\mathrm{Cr}$ ), cadmium $(\mathrm{Cd})$, lead $(\mathrm{Pb})$ and arsenic (As) in $\mathrm{CMC}$ and $\mathrm{CMC}_{\mathrm{R}}$ was measured by flame atomic absorption spectroscopy in a single beam Shimadzu AA6680 (Kyoto, Japan) spectrophotometer. The conditions used to set the equipment were similar to those described by Pohl et al. (2012). Prior to analysis, samples were subjected to a complete nitric acid/oxygen peroxide digestion and diluted with deionized water in a $10 \mathrm{~mL}$ calibrated flask.

\subsection{Statistics}

An analysis of variance (ANOVA) was conducted separately on the dependent variables studied in a one-way factorial design by using the Systat 12 statistical software (Chicago, IL, USA).


Fig. 1 - Effect of the incubation time and sodium hydroxide content on the yield, degree of substitution and degree of polymerization of carboxymethylation of SCF. Sodium hydroxide content: (口) 7.0 g/100 mL; (Ө) $10.5 \mathrm{~g} / 100 \mathrm{~mL}$.

The least significant differences (LSD) were calculated to compare the means at a level of $95 \%$ using the Fisher test.

\section{Results and discussion}

\subsection{Sludge effluent characterization}

Studies on paper sludge effluents reported numerous effects to the aquatic environment (Oikari et al., 1985). Thus, characterization of the effluents is the first step in the recycling paper challenge. Results in Table 1 depict the chemical oxygen demand, sedimentable solids at 10 and $60 \mathrm{~min}$, sludge effluent flow, total cellulose content and cellulose flow emission for the sludge effluents from the most significant emission points. Results of the chemical oxygen demand were similar to those obtained by Pereira et al. (2009) from a bleached Kraft pulp mill processing plant. Significant differences in all the parameters measured were found. The sedimentable solids 

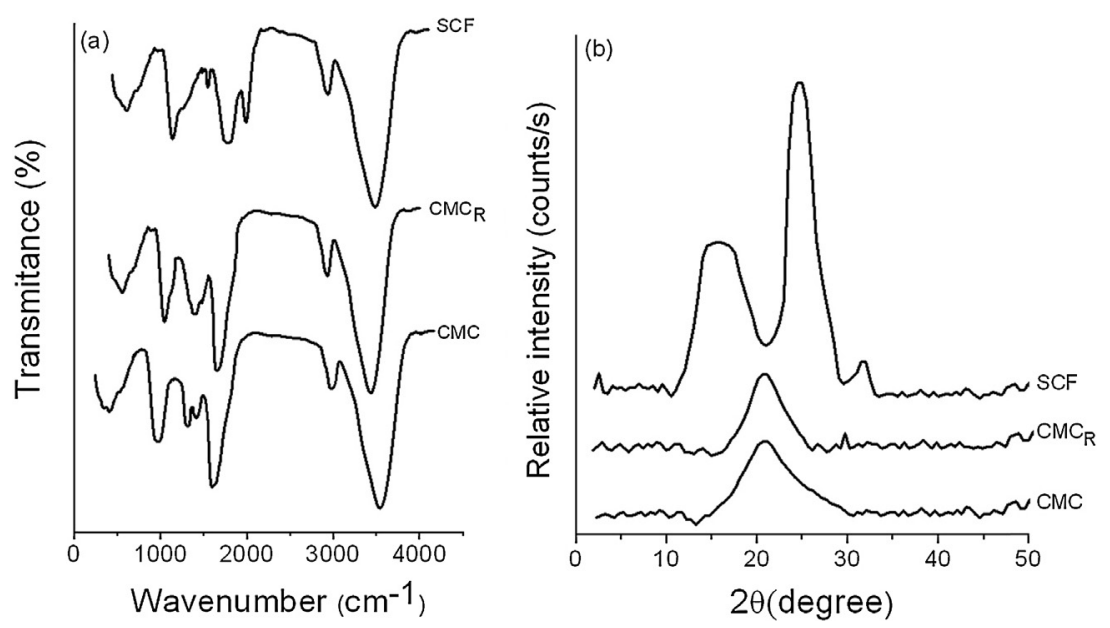

Fig. 2 - Spectroscopic characterization. (a) Infrared spectra, (b) X-ray diffraction pattern. Short cellulose fibers (SCF), commercial carboxymethylcellulose used as reference $\left(C M C_{R}\right)$ and carboxymethylcellulose obtained after $21 \mathrm{~h}$ of incubation (CMC).

at 10 and 60 min values could be associated with the quality of the fiber present in the samples, since short and damaged fibers require more time to sediment than longer and heavier fibers. From Table 1 it could be inferred that the cyclone effluent may have the highest SCF content due to sedimentable solids at $60 \mathrm{~min}$ and cellulose flow emission values, regarding the remaining samples. Therefore, SCF from the cyclone can be used as feedstock for the synthesis of CMC.

\subsection{CMC synthesis}

Fig. 1a depicts an increase in the yield of the reaction as the incubation time increased at both sodium hydroxide content, however, beyond $12 \mathrm{~h}$ of incubation the yield of the reaction is not modified. Probably, during the first part of the incubation an enhanced swelling of the SCF increased the accessibility of the reactants (Wang et al., 2010). However, the incubation of the reaction mixture more than $12 \mathrm{~h}$ leads to an increase of the sodium glycolate derived from the side reaction between sodium hydroxide and monochloro acetic acid reducing, thus; the increase of the yield reaction.

The solubility and swell ability of CMC were shown to be dependent on the degree of substitution (Toğrul and Arslan, 2003). Hence, this parameter needs to be controlled to optimize the properties of modified polysaccharides for specific manufacturing processes (Yuen et al., 2009). Fig. 1b showed an increase in the degree of substitution with the increase in the incubation time. On the other hand, the degree of substitution decreased when the sodium hydroxide content was shifted to higher values in concordance with results obtained by Pushpamalar et al. (2006) and Bhandari et al. (2012).
Measurement of the average degree of polymerization is of fundamental significance in aiding the elucidation of structure and functionality of complex carbohydrates. Although only the acid treatment cleavage the glycosidic bonds (Hubbell and Ragauskas, 2010), the pulping process and the carboxymethylation of the SCF may damage the structure of the cellulose decreasing its molecular weight. Fig. 1c showed no significant differences in the degree of polymerization at different incubation times or sodium hydroxide content, suggesting that this parameter is not affected by the studied variables. Similar values of degree of polymerization were obtained by Pala et al. (2007) in a secondary pulp obtained from a recovered paperboard using the viscosimetric method.

\subsection{Spectroscopic characterization}

Fig. 2a shows the infrared spectra of crude $\mathrm{SCF}, \mathrm{CMC}_{\mathrm{R}}$ and the CMC obtained after $21 \mathrm{~h}$ of incubation. The spectra of all samples show the typical absorptions of the cellulose backbone. The crude SCF spectrum showed similarities in the absorptions bands with the spectrum obtained by Pushpamalar et al. (2006) in sago pulp from sago waste suggesting similar chemical composition in both residues. The crude SCF spectrum depicts a broad absorption band at $3432 \mathrm{~cm}^{-1}$ corresponding to the stretching frequency of the $-\mathrm{OH}$ group. The band at $2920 \mathrm{~cm}^{-1}$ is due to the $\mathrm{C}-\mathrm{H}$ stretching vibration. The band at $1060 \mathrm{~cm}^{-1}$ is due to- $\mathrm{CH}-\mathrm{O}-\mathrm{CH}_{2}$ stretching (Kondo, 1997). A typical infrared spectrum obtained for $\mathrm{CMC}$ and $\mathrm{CMC}_{\mathrm{R}}$ shows the peak around $1650 \mathrm{~cm}^{-1}$ and $1400 \mathrm{~cm}^{-1}$ indicating the presence of the carboxymethyl substituent. The carboxylate ion gives rises to two bands: a strong asymmetrical stretching

Table 1 - Chemical oxygen demand (COD), sedimentable solids after 10 (SS 10) and 60 min (SS 60), sludge effluent flow (SEF), total cellulose content (TCC) and cellulose flow emission (CFE) for the sludge effluents from the most significant emission points.

\begin{tabular}{|c|c|c|c|c|c|c|}
\hline $\begin{array}{l}\text { Effluent } \\
\text { sample }\end{array}$ & $\mathrm{COD}(\mathrm{mg} / \mathrm{L})$ & $\mathrm{SS} 10(\mathrm{~mL} / \mathrm{L})$ & $\mathrm{SS} 60(\mathrm{~mL} / \mathrm{L})$ & $\operatorname{SEF}\left(\mathrm{m}_{3} / \mathrm{h}\right)$ & TCC (g/L) & CFE $(\mathrm{Kg} / \mathrm{h})$ \\
\hline Cyclone & $3206 \pm 285^{c}$ & $850 \pm 21^{c}$ & $650 \pm 13^{d}$ & $12.7 \pm 2.5^{a, b}$ & $9.05 \pm 1.24^{c}$ & $114.9 \pm 3.7^{d}$ \\
\hline Papermaker line & $1323 \pm 97^{a}$ & $300 \pm 14^{b}$ & $30 \pm 4^{a}$ & $9.0 \pm 3.3^{a}$ & $0.28 \pm 0.03^{a}$ & $2.5 \pm 1^{a}$ \\
\hline Recuperation tank & $1832 \pm 114^{b}$ & $100 \pm 7^{a}$ & $67 \pm 9^{b}$ & $9.5 \pm 2.5^{a}$ & $0.39 \pm 0.07^{a}$ & $3.7 \pm 1.1^{\mathrm{a}}$ \\
\hline Pulp thickener & $4858 \pm 253^{d}$ & $700 \pm 32^{d}$ & $425 \pm 38^{c}$ & $20.6 \pm 5.9^{b}$ & $3.85 \pm 1.4^{b}$ & $79.3 \pm 2.1^{b}$ \\
\hline
\end{tabular}




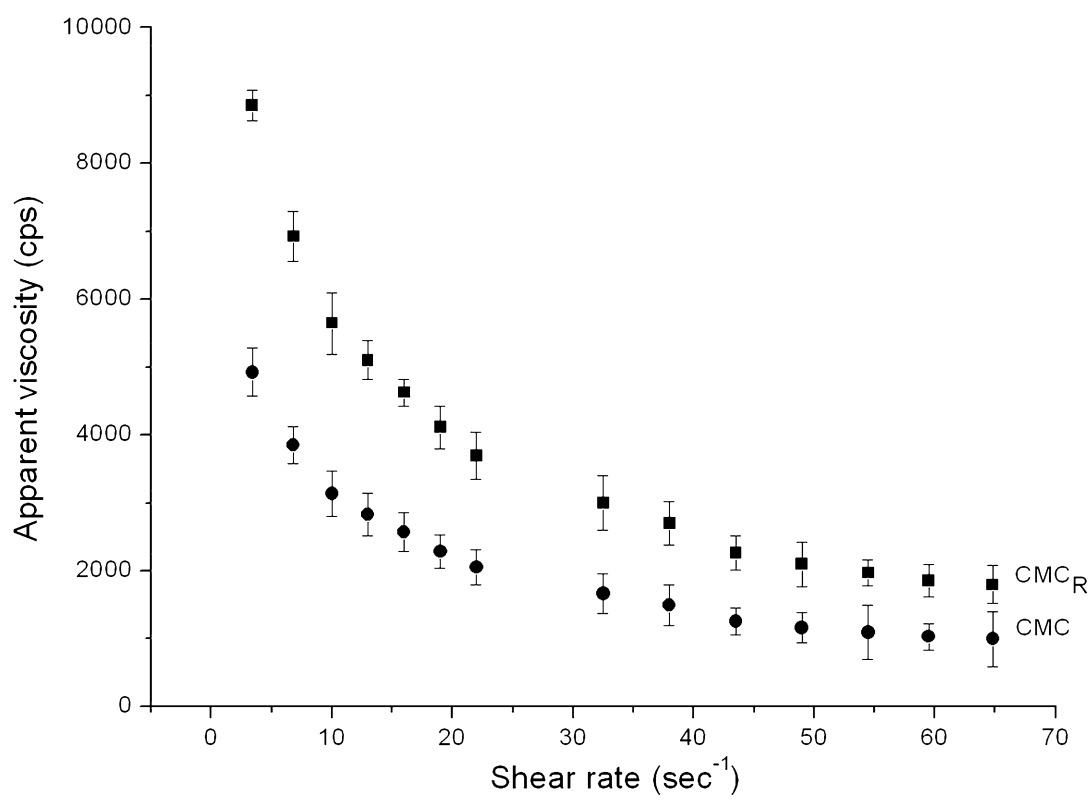

Fig. 3 - Effect of shear rate on the apparent viscosity of $1 \% \mathrm{w} / \mathrm{v}$ aqueous solution of commercial carboxymethylcellulose used as reference $\left(\mathrm{CMC}_{\mathrm{R}}\right)$ and carboxymethylcellulose obtained after $21 \mathrm{~h}$ of incubation (CMC).

band near $1650 \mathrm{~cm}^{-1}$ and a weaker symmetrical stretching band near $1400 \mathrm{~cm}^{-1}$. Two weak peaks near $1420 \mathrm{~cm}^{-1}$ and $1630 \mathrm{~cm}^{-1}$ in crude SCF were observed and were due to $-\mathrm{OH}$ bending vibration from absorbed water and $-\mathrm{CH}_{2}$ scissoring, respectively (Fakrul Alam and Mondal, 2013). Hence the occurrence of strong peaks in CMC confirmed the formation of this polymer by the process of etherification.

Fig. $2 \mathrm{~b}$ depicts the X-ray diffractogram for $\mathrm{SCF}, \mathrm{CMC}_{\mathrm{R}}$ and the CMC obtained after $21 \mathrm{~h}$ of incubation. The X-ray diffraction pattern of SCF showed a broad peak between $15^{\circ}$ and $17^{\circ}$ and two other peaks at $22.9^{\circ}$ and $32.7^{\circ}$ characteristic of cellulose-I crystalline structure coinciding with the results obtained by $\mathrm{He}$ et al. (2009) for paper sludge. On the other hand, the X-ray diffractograms of $\mathrm{CMC}_{\mathrm{R}}$ and $\mathrm{CMC}$ depicted the characteristics peaks of cellulose-II crystalline structure. This fact indicated that, prior to the carboxymethylation process, destruction of cellulose-I crystalline structure and formation of cellulose-II crystalline structure took place.

\subsection{Rheological characterization}

One of the main functional properties of CMC is its ability to control the rheology of hydrated systems. The flow properties of CMC was widely described in literature by several authors (Varshney et al., 2006; Díaz and Navaza, 2003; Yaşar et al., 2007) and all of them found a non Newtonian pseudoplastic behavior within a certain range of temperature and polymer concentration. A plot of the apparent viscosity values of the aqueous solutions of the CMC obtained after $21 \mathrm{~h}$ of incubation and $C M C_{R}$ versus shear rate (Fig. 3) showed that values of the apparent viscosity were dependent upon shear rate and decreased with increasing shear rate. This result not

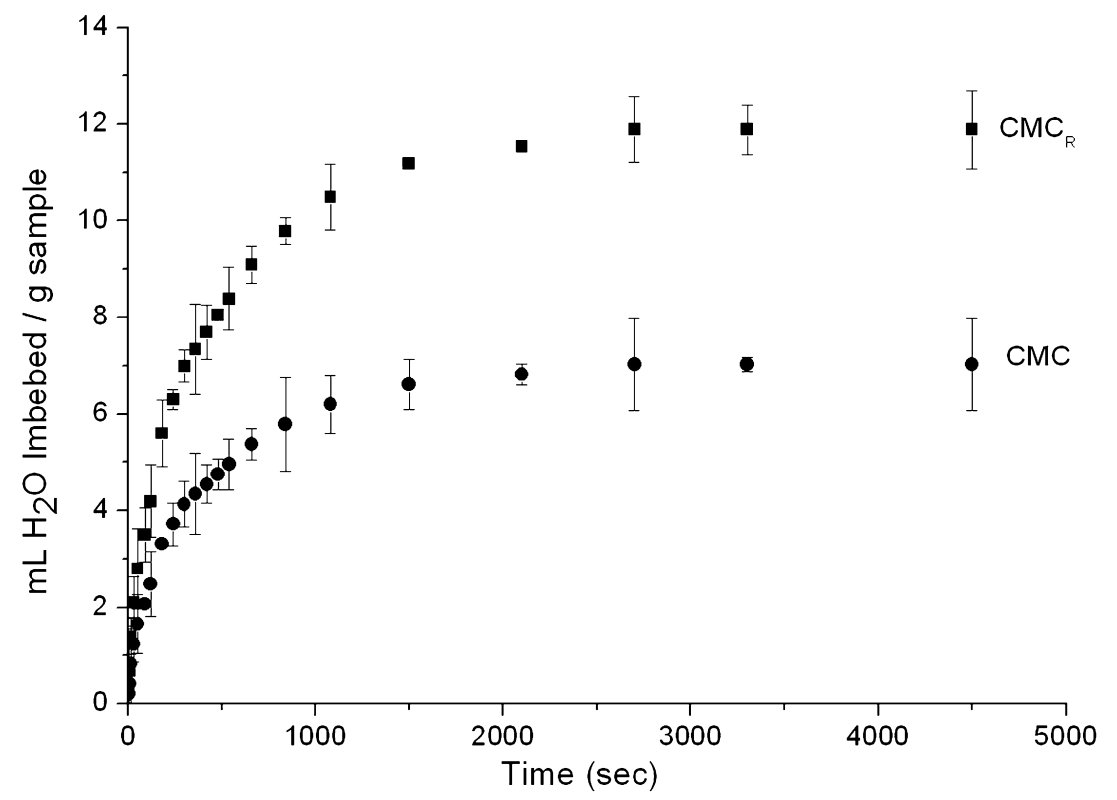

Fig. 4 - Water imbibing capacity of commercial carboxymethylcellulose used as reference $\left(\mathrm{CMC}_{\mathrm{R}}\right)$ and carboxymethylcellulose obtained after $21 \mathrm{~h}$ of incubation (CMC). 
Table 2 - Hunter's parameters $\left(L^{*}, a^{*}\right.$ and $\left.b^{*}\right)$, total color change $(\Delta E)$ and trace elements content of the commercial

carboxymethylcellulose used as reference $\left(C C_{R}\right)$, carboxymethylcellulose obtained after obtained after $21 \mathrm{~h}$ of

incubation (CMC), degree of polymerization (DP) and degree of substitution (DS).

\begin{tabular}{lllllllllll} 
& $\mathrm{L}^{*}$ & $a^{*}$ & $\mathrm{~b}^{*}$ & $\Delta E$ & $\mathrm{~Pb}(\mathrm{mg} / \mathrm{L})$ & $\mathrm{Cr}(\mathrm{mg} / \mathrm{L})$ & $\mathrm{Cd}(\mathrm{mg} / \mathrm{L})$ & As $(\mathrm{mg} / \mathrm{L})$ & $\mathrm{DS}$ & $\mathrm{DP}$ \\
\hline $\mathrm{CMC}_{\mathrm{R}}$ & $92.64^{\mathrm{a}}$ & $0.03^{\mathrm{a}}$ & $5.83^{\mathrm{a}}$ & 0 & $5.2^{\mathrm{a}}$ & $1.7^{\mathrm{a}}$ & $1.1^{\mathrm{a}}$ & $0.8^{\mathrm{a}}$ & $0.92^{\mathrm{b}}$ & $1405^{\mathrm{b}}$ \\
$\mathrm{CMC}$ & $66.57^{\mathrm{b}}$ & $-1.47^{\mathrm{b}}$ & $3.33^{\mathrm{b}}$ & 26.16 & $22.8^{\mathrm{b}}$ & $11.0^{\mathrm{b}}$ & $1.3^{\mathrm{a}}$ & $1.4^{\mathrm{a}}$ & $0.71^{\mathrm{a}}$ & $877.54^{\mathrm{a}}$ \\
\hline
\end{tabular}

Values in the same column with some letter in common are not significantly different $(P>0.05)$.

only confirms the pseudoplastic behavior of the CMC solutions reported by other authors (Varshney et al., 2006; Díaz and Navaza, 2003; Yaşar et al., 2007) but also confirms the success of the carboxymethylation of the crude SCF. In addition, viscosity values of $\mathrm{CMC}_{R}$ (degree of polymerization =1405) were higher than the obtained for the CMC (degree of polymerization around 860, Fig. 1c) within the entire shear rate assayed. This fact could be explained taking into account that a polymer with a high molecular weight, like the $C M C_{R}$, acquires a large hydrodynamic volume increasing the viscosity of the solution.

\subsection{Water imbibing capacity}

Commercially produced CMC is appreciated in different industries due to its ability to interact with water, that is, the water spontaneously imbibed or the water imbibing capacity. Fig. 4 showed that the water imbibing capacity of the $C M C_{R}$ $(11.88 \mathrm{~mL} / \mathrm{g})$ was higher than the CMC $(7.0 \mathrm{~mL} / \mathrm{g})$. This property depends on the interactions of a substance with water. Usually this interaction has an electrostatic nature and other molecules could interfere between the carboxyl groups of the CMC and water. Probably the unremoved contaminants and the lower degree of substitution of the CMC would explain the lower water imbibing capacity. Bhandari et al. (2012) also reported a lower water absorption power in a CMC with a low degree of substitution.

\subsection{Color properties of the CMC}

Results in Table 2 depict significant differences in the color properties of the $\mathrm{CMC}_{\mathrm{R}}$ and $\mathrm{CMC}$. The $\mathrm{CMC}_{\mathrm{R}}$ was more clear, reddish and yellowish than the other. Results of the total color difference $(\Delta E)$ reveal that $C M C$ is darker, probably due to the presence of impurities.

\subsection{Trace elements analysis}

The trace element composition of CMC is related to the composition of the starter material, that is, the crude SCF. Results (Table 2) indicated that the content of $\mathrm{Pb}$ and $\mathrm{Cr}$ exceeds the limit of the Argentinean regulations (ANMAT, 2004). Therefore, the CMC obtained could be used in industries such as paint factories or building materials. Monte et al. (2009) obtained similar values of $\mathrm{Pb}$ and $\mathrm{Cr}$ and lower values of $\mathrm{Cd}$ in a biological sludge from mechanical pulp mill. This fact suggests that in order to obtain a high quality product some steps of metal purification should be included in the recycling process. On the other hand, the content of $\mathrm{Cd}$ and As was within the limits of regulations.

\section{Conclusion}

Incubation time slightly increased the yield of the reaction and the degree of substitution during the first $12 \mathrm{~h}$. The reaction yield and degree of substitution both decreased when the initially concentration of sodium hydroxide was increased from $7.0 \mathrm{~g} / \mathrm{mL}$ to $10.5 \mathrm{~g} / \mathrm{mL}$. The degree of polymerization was not affected by the incubation time and sodium hydroxide concentration.

The CMC obtained was darker than the reference and the content of $\mathrm{Cr}$ and $\mathrm{Pb}$ exceeds the maximum allowed by regulatory organism. The hydration properties were also lower than the reference.

Results of the present work demonstrates that it is possible to obtain CMC using crude SCF as raw material and provides a feasible alternative way for generating a value added product and contributing to solving, at least in part, some of the environmental problems derived from paper industry.

\section{Acknowledgements}

The authors would like to acknowledge to Facultad de Ciencias Exactas (UNLP) for financial support and to Comisión de Investigaciones Científicas de la Provincia de Buenos Aires (CIC-PBA) and Centro de Investigación y Desarrollo en Criotecnología de Alimentos (CIDCA), for providing the working place.

\section{References}

Andreola, F., Barbieri, L., Lancellotti, I., Pozzi, P., 2005. Recycling industrial waste in brick manufacture. Part 1. Mater. Cons. 55, 5-16.

ANMAT, 2004. Código Alimentario Argentino (Food Code of Argentina, Chapter XVIII: food additives, art. 1398, Res 2227, 22.5.73), http://www.anmat.gov.ar/alimentos/codigoa/ CAPITULO_XVIII.pdf (09/01/2014)

ASTM (American Society for Testing and Materials), 1991. Method 1739-89. Standard test method for the collection and measurements of Dustfall (settleable particulate matter). In: Canning, et al. (Eds.), Atmospheric analysis: Occupational Health and Safety. ASTM (American Society for Testing and Materials), Philadelphia.

Barai, B.K., Singhal, R.S., Kulkarni, P.R., 1997. Optimization of a process for preparing carboxymethyl cellulose from water hyacinth (Eichornia crassipes). Carbohydr. Polym. 32, 229-231.

Bhandari, P.N., Jones, D.D., Hanna, M.A., 2012. Carboxymethylation of cellulose using reactive extrusion. Carbohydrate 87, 2246-2254.

Bos, M.G., 1989. In: Bos, M.G. (Ed.), Discharge Measurement Structures. International Institute for Land Reclamation and Improvement, Wageningen, The Netherlands, pp. 334-335 (Chapter 9).

Choy, K.K.H., Ko, D.C.K., Cheung, W.H., Fung, J.S.C., Hui, D.C.W., Porter, J.F., McKay, G., 2004. Municipal solid waste utilization for integrated cement processing with waste minimization. A pilot scale proposal. Process Saf. Environ. Prot. 82, 200-207. 
Díaz, D.G., Navaza, J.M., 2003. Rheology of aqueous solutions of food additives effect of concentration, temperature and blending. J. Food Eng. 56, 387-392.

Eroglu, V., Saatci, A.M., 1993. Reuse of sludge from pulp and paper industry pilot and full-scale applications. Water Sci. Technol. 28, 17-26.

Fakrul Alam, A.B.M., Mondal, I.H., 2013. Utilization of cellulosic wastes in textile and garment industries. I. Synthesis and grafting characterization of carboxymethyl cellulose from knitted rag. J. Appl. Polym. Sci. 128, 1206-1212.

Geng, X., Deng, J., Zhang, S.Y., 2007. Paper mill sludge as a component of wood adhesive formulation. Holzforschung 61, 688-692.

Gottipati, R., Mishra, S., 2011. A kinetic study on pyrolysis and combustion characteristics of oil cakes: effect of cellulose and lignin content. J. Fuel Chem. Technol. 39, 265-270.

He, X., Wu, S., Fu, D., Ni, J., 2009a. Preparation of sodium carboxymethyl cellulose from paper sludge. J. Chem. Technol. Biotechnol. 84, 427-434.

He, J., Lange, C.R., Dougherty, M., 2009b. Laboratory study using paper mill lime mud for agronomic benefit. Process Saf. Environ. Prot. 87, 401-405.

Heinze, T., Koschella, A., 2005. Carboxymethyl ethers of cellulose and starch-a review. Macromol. Symp. 223, 13-39.

Hubbell, C.A., Ragauskas, A.J., 2010. Effect of acid-chlorite delignification on cellulose degree of polymerization. Bioresour. Technol. 101, 7410-7415.

Kondo, T., 1997. The assignment of IR absorption bands due to free hydroxyl groups in cellulose. Cellulose 4, 281-292.

Khullar, R., Varshney, V.K., Naithani, S., Heinze, T., Soni, P.L., 2005. Carboxymethylation of cellulosic material (Average Degree of Polymerization 2600) isolated from cotton (Gossypium) linters with respect to degree of substitution and rheological behavior. J. Appl. Polym. Sci. 96, 1477-1482.

Monte, M.C., Fuente, E., Blanco, A., Negro, C., 2009. Waste management from pulp and paper production in the European Union. Waste Manage. 29, 293-308.

Naik, T.R., Friberg, T.S., Chun, Y.M., 2004. Use of pulp and paper mill residual solids in production of cellucrete. Cem. Concr. Res. 34, 1229-1234.

Ochoa de Alda, J.A.G., 2008. Feasibility of recycling pulp and paper mill sludge in the paper and board industries. Resour. Conserv. Recycl. 52, 965-972.
Oikari, A., Nikinmaa, M., Lindgren, S., Lonn, B., 1985. Sublethal effects of simulated pulp mill effluents on the respiration and energy metabolism of rainbow trout (Salmo gairdneri). Ecotoxicol. Environ. Saf. 9, 378-384.

Pala, H., Mota, M., Gama, F.M., 2007. Enzymatic depolymerization of cellulose. Carbohydr. Polym. 68, 101-108.

Pereira, R., Antunes, S.C., Gonçalves, A.M., Marques, S.M., Gonçalves, F., Ferreira, F., Freitas, A.C., Roha santos, T.A., Diniz, M.S., Castro, L., Peres, I., Duarte, A.C., 2009. The effectiveness of a biological treatment with Rhizopus oryzae and of a photo-fenton oxidation in the mitigation of toxicity of a bleached kraft pulp mill effluent. Water Res. 43, 2471-2480.

Pohl, P., Stecka, H., Greda, K., Jamroz, P., 2012. Bioaccessibility of $\mathrm{Ca}, \mathrm{Cu}, \mathrm{Fe}, \mathrm{Mg}, \mathrm{Mn}$ and $\mathrm{Zn}$ from commercial bee honeys. Food Chem. 134, 392-396.

Pushpamalar, V., Langford, S.J., Ahmad, M., Lim, Y.Y., 2006. Optimization of reaction conditions for preparing carboxymethyl cellulose from sago waste. Carbohydrate 64, 312-318.

Toğrul, H., Arslan, N., 2003. Production of carboxymethyl cellulose from sugar beet pulp cellulose and rheological behaviour of carboxymethyl cellulose. Carbohydr. Polym. 54, 73-82.

Varshney, V.K., Gupta, P.K., Naithani, S., Khullar, R., Bhatt, A., Soni, P.L., 2006. Carboxymethylation of a-cellulose isolated from Lantana camara with respect to degree of substitution and rheological behavior. Carbohydr. Polym. 63, 40-45

Wagner, J.R., Sorgentini, D.A., Añon, M.C., 1996. Thermal and electrophoretic behavior, hydrophobicity, and some functional properties of acid-treated soy isolates. J. Agric. Food Chem. 44, 1881-1889.

Wang, L.F., Pan, S.Y., Hu, H., Miao, W.H., Xu, X.Y., 2010. Synthesis and properties of carboxymethyl kudzu root starch. Carbohydr. Polym. 80, 174-179.

Yaşar, F., Toğrul, H., Arslan, N., 2007. Flow properties of cellulose and carboxymethyl cellulose from orange peel. J. Food Eng. 81, 187-199.

Yuen, S.N., Choi, S.M., Phillips, D.L., Ma, C.Y., 2009. Raman and FTIR spectroscopic study of carboxymethylated non-starch polysaccharides. Food Chem. 114, 1091-1098. 